\title{
Educational Program for Nurses Regarding Management of Children with Maple Syrup Urine Disease during Acute Intermittent Late- Onset
}

\author{
Samah Mostafa Khalaf \& Khadiga Mohammed Said \\ Lecturer of Pediatric Nursing, Faculty of Nursing, Benha University, Egypt
}

\begin{abstract}
Background: Maple syrup disease (MSD) is an inherited metabolic disease that has the capacity to kill or cause severe neurological damage to children at early years of life. The aim of this study was to evaluate the effect of Educational Program on nurses' management of children with Maple Syrup Urine Disease during acute intermittent late-onset. A quasi experimental design was used to conduct this study. Settings: The study was carried out in the Pediatric unit and hereditary unit at Ain Shams Specialized Hospital for children affiliated to Ain shams University. Sample: A convenient sample of all nurses working in pediatric and hereditary units (80 bedside male and female nurses) from the beginning of February 2016 to the end of July 2016. Two tools were utilized to collect data for this study; A structured Interviewing questionnaire sheet, and observational checklists regarding nursing care provided for children with MSUD. Results: nurses' knowledge regarding MSUD was unsatisfactory on pre - program phase, while there is a significant statistical difference pre and post program implementation. There is a positive relation between nurses' knowledge, practice and personal data pre and post program implementation. Conclusion: There is an improvement in nurses' practice between pre and post program implementation regarding management of children with MSUD. The study revealed that the program had positive effect on the nurses' knowledge and practice towards management of children with MSUD. Recommendations: The study recommended that continuous education and training sessions about management of children with MSUD should be provided to upgrade nurses' knowledge and improve their practice level. Availability and accessibility of printed universal guidelines and standard precautions regarding MSUD.
\end{abstract}

Key words: Nurses' Management, Educational Program, and Maple Syrup Urine Disease

\section{Introduction}

Maple Syrup Urine Disease (MSUD) is an inherited metabolic disorders (IMD), caused by branched-chain $\alpha$-ketoacid dehydrogenase (BCKD) deficiency which resulting in the accumulation of the branched chain amino acids (BCAA), leucine (LEU), isoleucine (ILE), and valine (VAL) and their corresponding $\alpha$-ketoacids (BCKA) (Singh et al., 2013). Moreover, it characterized by the inability to metabolize the branched chain amino acids leucine, isoleucine, and valine, hence, resulting in their accumulation in the blood. The name of the disease derives from the characteristic sweet maple syrupy smell of urine in affected patients (Joshi \& Venugopalan, 2007).

The worldwide incidence of MSUD is approximately 1:185,000. Although there are areas of much higher incidence, such as among the old-order Mennonite community where the incidence may be as high as 1:200 births, most clinics see very few individuals with MSUD. With such small patient populations, it is difficult to accumulate outcome data except through multicenter collaboration. The majority of publications are case studies and case series, often retrospective and lack data from age-matched controls. But, according to Right Diagnosis, 2012, the prevalence rate of MSUD in Egypt was 197,707 (Wilcken, 2012).

The disease appears in early infancy, where, it characterized by feeding difficulties, refusal of food, vomiting, seizures, lack of energy, and even coma. So, if the child left untreated, the accumulation of the amino acids and their keto acids will lead to serious complications, including; encephalopathy and progressive neurodegeneration. MSUD manifests itself in a range of severity, ranging from a classic form to an intermittent form, to a mild form. In the severe form, severe acidosis may be presented during the first few weeks of life, which unless treated, it may be fatal. Even the affected children with the mild form display mental retardation and bouts of acidosis (Hoffmann et al., 2006).

Infants with untreated early onset (classic) MSUD have significant developmental delay and die within the first months of life. Children or juveniles with late-onset (ie, intermediate, intermittent) forms of MSUD may have some forms of developmental delay depending on the residual activity of BCKD. So, all children are at increased risk for metabolic de-compensation during periods of increased protein catabolism (e.g, inter-current 
illness, trauma, surgery). Morbidity can almost entirely be prevented with early diagnosis in neonates younger than 10 days, with appropriate treatment at presentation and during episodes of potential metabolic decompensation (Quental et al., 2008).

There are two main treatment aspects for managing maple syrup urine disease (MSUD) in children they includes; long-term management and treatment of acute metabolic de-compensation episodes. Additionally, the mainstay in the treatment of MSUD is dietary restriction of branched-chain amino acids (Park et al., 2011).

The goal of dietary therapy is normalization of branched-chain amino acids (particularly of leucine) by restricting intake of branched-chain amino acids without impairing growth and intellectual development. Dietary therapy must be life-long. Several commercially available formulas and foods are available without branchedchain amino acids or with reduced levels of branched-chain amino acids. Products are available for juveniles and adults, such as MSUD Express. The intake of leucine is calculated on an individual basis following the measurement of plasma branched-chain amino acids. Measure plasma amino acid levels on a regular basis at appropriate intervals for the first 6-12 months of life. In addition to dietary therapy, administer thiamine (10-20 $\mathrm{mg} / \mathrm{d}$ ) for 4 weeks to determine thiamine responsiveness (Mazariegos et al., 2012).

Nurses are playing an important role in management of children with MSUD. They provide ongoing support for the children and their parents, advising on the most appropriate diet and keeping them up-to-date with any developments in the treatment of MSUD. Nursing observation and attention to detail is vital. The reporting of episodes of vomiting or diarrhea or headache and instigation of treatment may be life-saving. Nurses, have a great role in supporting the family in feeling positive toward raising and caring for these children (Yamaguchi et al., 2016).

\section{Significance of the study:}

The management of metabolic disorders is complex and demands dedicated input from the multidisciplinary team led by a metabolic consultant. A holistic and family centred approach is used by the heath team, with input from medical, nursing, dietetic, psychology, social work, genetic counselling, physiotherapy, laboratory staff and play specialist staff. So, advancing the education of nurses involved in the diagnosis, care during acute intermittent episodes and treatment of such children and to promote research into the treatment of inherited metabolic diseases.

\section{Aim of the study:}

The aim of this study was to evaluate the effect of designed educational program on nurses' management of children with Maple Syrup Urine Disease during Acute Intermittent Late- Onset through:

- Assessing nurses' knowledge and practice regarding Maple Syrup Urine Disease.

- Designing and implementing educational program based on nurses' actual needs assessment about Maple Syrup Urine Disease

- Evaluating the effect of implemented educational program on nurses' knowledge and practice toward

\section{Research Hypotheses:} care of children with MSUD.

- The designed educational program will upgrade nurses' knowledge and improve their practice regarding care of children with Maple Syrup Urine Disease.

- There are significant relationships between nurses' knowledge and practice regarding care of children with Maple Syrup Urine Disease and their personal characteristics

\section{Research Design:}

\section{Subjects and Method}

\section{Settings:}

A quasi experimental design was used to conduct this study.

The study was carried out in the Pediatric unit and hereditary unit at Ain Shams Specialized Hospital for children.

\section{Sampling:}

Aconvenient sample of 80 bedside male and female nurses working in pediatric unit at Ain Shams Specialized Hospital for children affiliated to Ain Shams University, through two shifts (morning and, afternoon shifts) for a period of six months from the beginning of February 2016 to the end of July 2016.

\section{Tools of data collection:}

Two tools were utilized to collect data of the current study. They were developed by the researchers. These tools were consisted of the following: 
Tool I: A Structured Interviewing Questionnaire Sheet: it was developed by the researchers based on the scientific literatures (Quental et al., 2008, Mazariegos et al., \& 2012, Singh et al., 2013). It was prepared in Arabic language to suite the culture of Egyptian nurses and to assess the nurses' knowledge regarding MSUD. Each nurse was interviewed individually for answering the knowledge questionnaire sheet. It comprised two main parts which are:

Part I: Personal characteristic of the studied nurses as; age, gender, qualifications, years of experience and attendance of training courses regarding metabolic disorders.

Part II: Nurses' knowledge about MSUD, which consisted of multiple choice questions and close ended questions covering the questions related to; definition, causes, signs and symptoms of the disease, types, risk signs of acute phase, complications, diet restriction, prevention and nursing management. The scoring system consisted of giving score (1) for the correct answer and (0) for the incorrect answer. The total questions composed of ( 9 questions)

The scoring system for knowledge classified as follows:

- Satisfactory knowledge level: Equal to or more than $60 \%$

- Unsatisfactory knowledge level: Less than $60 \%$

Tool (II): Observational Checklist: It was adopted from (Hockenberry and Wilson (2011), and National Centre for Inherited Metabolic Disorders, 2014) and modified by the researchers to suit the Egyptian culture. It was used to assess the actual nurses' practices regarding care of children with MSUD in relation to ; general observations (5 items), neurological status(6 items), nutrition and medication (6 items), blood, urine sampling, and intake and output(5 items)and ongoing education and genetic implications( 4 items)

Total practice scores were (26 items). Each nurse was observed during each procedure for three different times using nurses' observational check lists. The mean of the three observations was calculated and the mean was taken.

The scoring system for practice classified as follows:

- Competent practice level: Equal to or more than $80 \%$

- Incompetent practice level: Less than $80 \%$

\section{Validity and reliability}

\section{Preparatory phase}

The researchers reviewed the past, current regional and international related literature covering all aspects of the study using textbooks, articles, journal, websites and scientific magazines. This helped the researchers to be acquainted with the research problem and guided them in developing the study tools. To measure content validity of the study tools, the researchers assure that items of the tools were adequately represent what are supposed to measure by five experts including; one medical-surgical nursing, one pediatric medicine, and three of pediatric nursing field from the Faculty of Nursing Cairo, El-Menofia and Benha Universities, to test the content validity. Modifications of the tools were done according to the expert's judgment on clarity of sentences, appropriateness of content and sequence of items. The experts' agreed on the content, but recommended minor language changes that would make the information clearer and more precise. The suggested changes were made. Internal consistency reliability of all items of the tools was assessed using coefficient alpha. It was 0.83 for structured interviewed questionnaires sheet, was 0.86 for nurses practices observation checklist.

\section{Exploratory phase:}

\section{Ethical Considerations and Human Rights:}

An official permission to conduct the study was obtained from the hospital mangers. Then participation in the study was voluntary; each nurse was informed about the purpose, procedure, benefits, and nature of the study and each nurse had the right to withdraw from the study at any time without any rationale, then oral/written consent obtained from them. Subjects were informed that obtained data will not be included in any further researches. Confidentiality and anonymity of each subject was assured through coding of all data and all information has taken was protected

\section{Pilot study:}

A pilot study was carried out on 10\% of total sample size (8) nurses over a period of one month (January 2016) to test feasibility, clarity, objectivity and applicability of the study tools. Carrying out the pilot study gave the researchers experience to deal with the included study subjects, and the data collection tools. Based on the 
results of the pilot study, needed modifications were done and pilot study subjects were excluded from the actual study sample.

\section{Field work:}

The field work was performed from the beginning of February 2016 to the end of July 2016 to collect data by the researchers. The researchers were available three days per week (Saturday, Monday, and Tuesday) in the morning and afternoon shifts. The numbers of nurses who were assessed and taking educational program per week were ranged from 7-10 nurses. The structured interviewing questionnaire sheet was filled out by the nurse and observational checklists were collected by the researchers and the average times required for completion of each tool was around 15-25 minutes. The same researcher was observing the nurses' practice regarding care of children with MSUD for the same specified nurse during their practices.

\section{Procedure:}

\section{- Preparation phase:}

It was concerned with designing and testing different data collection tools, in addition, the administrative arrangements to carry out the study as well as to conduct the pilot study. In the beginning, the researchers introduce themselves to the studied nurses. Nurses who accept to participate in the study individually interviewed by the researchers to explain the nature, purpose, and the desired outcomes of the study and oral/written consent was obtained from these nurses.

\section{- Implementing phase:}

Data were collected from the beginning of February 2016 to the end of July 2016. The researchers attended the selected study settings three times weekly during their working shifts (Saturday, Monday, and Tuesday) in the morning and afternoon shifts by rotation in the previously mentioned study settings. Each nurse was interviewed individually for $15-20$ minutes to fill out the structured interviewing questionnaire sheet (Tool 1). The researchers clarified and answered any related questions. Then, each nurse was observed during their practice on morning and afternoon shifts using nurses observational check lists by the same researcher (Tool 2). The time needed for each observation for each nurse was 20-25 minutes for three times during providing of care of children with MSUD. The same researcher was observing the nurses' practice regarding care of children with MSUD for the same specified nurse during their practices. The mean of the three observations was calculated after that, the mean was taken.

\section{- Program Construction, Implementation, and Evaluation:}

The educational program was designed based on the actual needs assessment of nurses then implemented and evaluated. The aim of this program was to upgrade nurses' knowledge and improve their practice regarding care of children with Maple Syrup Urine Disease. The implementation of the educational program was carried out in the previously mentioned study settings. The guiding booklet was distributed and implemented with the studied nurses whereas, the researchers explained the contents of the guiding booklet and how to use as a personal reference later on. Training of nurses was conducted using a laptop with MS Power Point presentations 2010 made from contents of the guiding booklet. The program was implemented for a group of nurses that entail (7-10) according to working circumstances, there mental and physical readiness.

The educational program was implemented over three weeks period in addition to one week for pre and post-test. A time schedule suitable for nurses was developed to conduct the program that included; date, place, topic, time and duration of each session. The total numbers of sessions were 9 sessions for theory and practice (3 for theory and 6 for practice) in each setting, each session took about 45 to 60 minutes include periods of discussion during their training. In addition to 2 sessions for pre-test and post-test.

At the beginning of the first session an orientation of the program, its importance and outcomes were explained. In addition, a feedback about the previous session was done and the objectives of the new topic were explained. Simple words and Arabic language were used to suite the nurses' level of understanding. At the end of each session, nurses' questions were discussed to correct any misunderstanding. In addition to re-demonstration for practical procedures.

Different teaching strategies were used for implementation of the program such as lectures, small group discussion, brain storming, role play, demonstration and re-demonstration using real objects. Suitable teaching aids as booklet, colored posters, doll and real objects were prepared especially for practice. Nurses were motivated to cooperate and participate actively in different stages of the study. 


\section{Evaluation:}

Upon the completion of the educational program the post test was done for the study sample to evaluate the outcomes of the implemented program using the same tools for data collection.

\section{Administrative design}

An official permission for data collection was obtained from the hospital manager and head of Pediatric unit and hereditary unit at Ain Shams Specialized Hospital for children through submission of official letters issued from the dean of Benha faculty of nursing. The title, objectives, and outcomes of the study were illustrated as well as the main data items to be covered, and the study was carried out after gaining the necessary permission.

\section{Statistical design}

The collected data were revised, organized, tabulated and analyzed by using SPSS (Statistical Package for the social Science Software) statistical package version 20 on IBM compatible computer. Numerical data (Quantitative data) was presented in tables by using Mean, Standard deviation $(\mathrm{X} \pm \mathrm{SD})$ and analyzed by applying t-test for normally distributed variables, while qualitative data were expressed as frequency and percentage and chi-square was used. Additionally, other statistical tests such as Independent t test. $t$ test was used as a parametric test of significance for comparison between two samples means. Pearson correlation (r) was used to measure the correlation between quantitative variables.

P-value at .05 was used to determine significance regarding:

- P-value $>.05$ to be statistically insignificant.

- P-value $\leq 05$ to be statistically significant.

- P-value $\leq 001$ to be high statistically significant.

Results:

Table (1): Number and percentage distribution of the studied nurses according to their Personal characteristics $(\mathbf{n}=\mathbf{8 0})$

\begin{tabular}{|c|c|c|}
\hline \multirow[t]{2}{*}{ Personal characteristics } & \multicolumn{2}{|c|}{$\begin{array}{c}\text { Study sample } \\
\mathrm{N}=\mathbf{8 0}\end{array}$} \\
\hline & No & $\%$ \\
\hline \multicolumn{3}{|l|}{ Age in years } \\
\hline - $20-<30$ & 54 & 67,50 \\
\hline - $30-<40$ & 25 & 31,2 \\
\hline - $\quad \geq 40$ & 1 & 1,3 \\
\hline \multicolumn{3}{|c|}{$\mathbf{X} \pm$ SD: $26.96 \pm 5.561$} \\
\hline \multicolumn{3}{|l|}{ Gender: } \\
\hline - $\quad$ Male & 9 & 11.2 \\
\hline - $\quad$ Female & 71 & 88.80 \\
\hline \multicolumn{3}{|l|}{ Educational level } \\
\hline - Diploma & 62 & 77.50 \\
\hline - $\quad$ Technical & 7 & 8.80 \\
\hline - $\quad$ Bachelor degree in nursing & 11 & 13.80 \\
\hline \multicolumn{3}{|l|}{ Years of experience } \\
\hline - $\quad<1$ year & 0 & 0.0 \\
\hline - $1-<10$ years & 64 & 80.00 \\
\hline - $\quad \geq 10$ years & 16 & 20.00 \\
\hline \multicolumn{3}{|c|}{$\mathrm{X} \pm \mathrm{SD}=6.76 \pm 4.77$} \\
\hline \multicolumn{3}{|c|}{$\begin{array}{l}\text { Attendance of previous training courses regarding Metabolic } \\
\text { disorders }\end{array}$} \\
\hline - yes & 0 & 00.0 \\
\hline - $\quad \mathrm{No}$ & 80 & 100,0 \\
\hline
\end{tabular}


As illustrated in table 1, the majority of the nurses' age was between 20 to less than 30 years with the mean age 26, $96+5,561$ years. The majority of them were female $88.8 \%$ ) and $77.5 \%$ had secondary school diploma in nursing. Additionally, $80.0 \%$ of them had years of experience less than 10 years, while no one of them attending training courses regarding metabolic disorders.

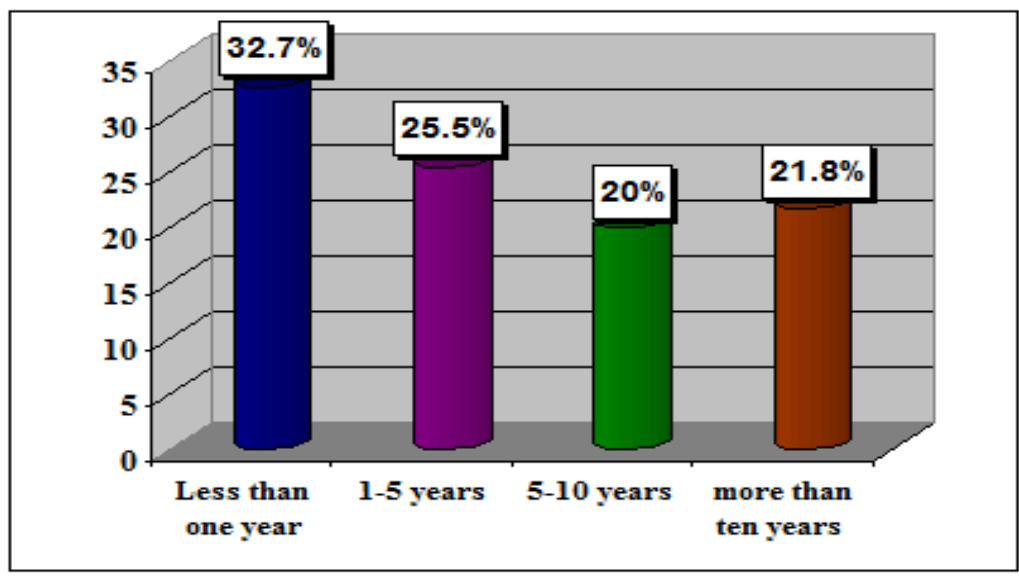

Figure (1): Percentage distribution of the studied children according to their age.

This figure shows that nearly one third $(32.7 \%)$ of the studied children less than one year of age. But the least of the studied children $(20 \%)$ from 5-10 years.

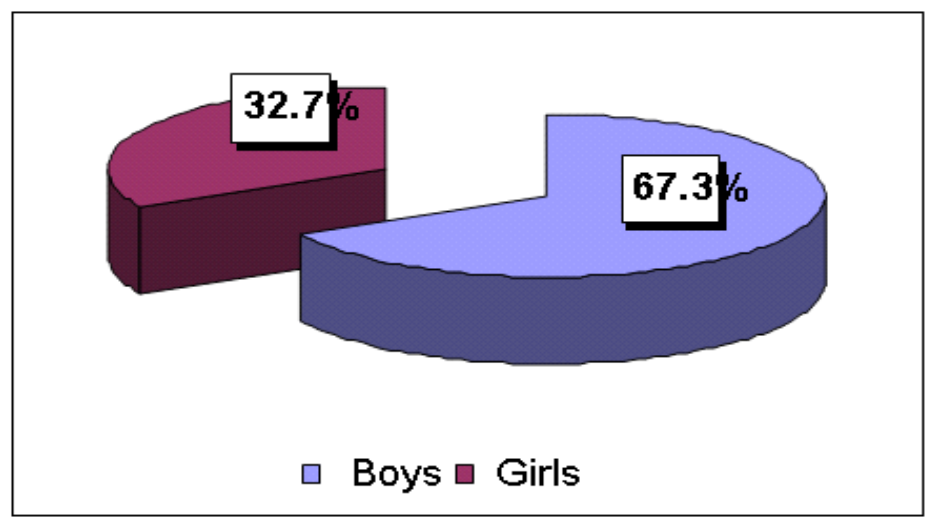

Figure (2): Distribution of the studied children according to their gender.

Figure 2; shows that more than two thirds $(67.3 \%)$ of the studied children were boys.

Table (2): Percentage distribution of the studied nurses according to their knowledge about Maple Syrup Urine Disease pre and post program implementation $(\mathbf{n}=\mathbf{8 0})$

\begin{tabular}{|c|c|c|c|c|c|c|}
\hline \multirow[t]{2}{*}{ Items } & \multicolumn{2}{|c|}{$\begin{array}{c}\text { Pre program } \\
\text { implementation } \\
(80)\end{array}$} & \multicolumn{2}{|c|}{$\begin{array}{c}\text { Post program } \\
\text { implementation } \\
(80)\end{array}$} & \multirow[t]{2}{*}{$\mathbf{X}^{2}$} & \multirow[t]{2}{*}{$P$ value } \\
\hline & No & $\%$ & No & $\%$ & & \\
\hline \multicolumn{5}{|l|}{ Definition } & \multirow{3}{*}{62.85} & \multirow{3}{*}{$0.000^{* *}$} \\
\hline - Correct & 18 & 22.50 & 68 & 85.00 & & \\
\hline - Incorrect & 62 & 77.50 & 12 & 15.00 & & \\
\hline \multicolumn{6}{|l|}{ Causes } & \multirow{3}{*}{$0.000^{* *}$} \\
\hline - Correct & 32 & 40.00 & 54 & 67.5 & \multirow[t]{2}{*}{12.16} & \\
\hline - Incorrect & 48 & 60.00 & 26 & 32.5 & & \\
\hline \multicolumn{6}{|c|}{ Signs and symptoms } & \\
\hline - $\quad$ Correct & 19 & 23.80 & 65 & 81.3 & \multirow[t]{2}{*}{53.03} & \multirow[b]{2}{*}{$0.000^{* *}$} \\
\hline - Incorrect & 61 & 76.30 & 15 & 18.8 & & \\
\hline
\end{tabular}


Effect of Educational Program on Nurses' Management...

\begin{tabular}{|c|c|c|c|c|c|c|}
\hline \multicolumn{6}{|l|}{ Types } & \multirow[b]{3}{*}{$0.000^{* *}$} \\
\hline - $\quad$ Correct & 7 & 8.80 & 63 & 78.8 & \multirow[t]{2}{*}{79.64} & \\
\hline - Incorrect & 73 & 91.30 & 17 & 21.3 & & \\
\hline \multicolumn{7}{|c|}{ Risk signs of acute stage } \\
\hline - $\quad$ Correct & 32 & 40.00 & 67 & 83.8 & \multirow[t]{2}{*}{32.45} & \multirow[b]{2}{*}{$0.000^{* *}$} \\
\hline - $\quad$ Incorrect & 48 & 60.00 & 13 & 16.3 & & \\
\hline \multicolumn{7}{|l|}{ Complications } \\
\hline - Correct & 18 & 22.50 & 64 & 80.00 & \multirow[t]{2}{*}{52.93} & \multirow[t]{2}{*}{$0.000^{* *}$} \\
\hline - $\quad$ Incorrect & 62 & 77.50 & 16 & 20.00 & & \\
\hline \multicolumn{7}{|l|}{ Diet restriction } \\
\hline - $\quad$ Correct & 28 & 35.00 & 59 & 73.8 & \multirow[t]{2}{*}{24.21} & \multirow[t]{2}{*}{$0.000^{* * *}$} \\
\hline - $\quad$ Incorrect & 52 & 65.00 & 21 & 26.3 & & \\
\hline \multicolumn{7}{|l|}{ Treatment } \\
\hline - $\quad$ Correct & 32 & 40.00 & 53 & 66.3 & \multirow[t]{2}{*}{11.06} & \multirow[t]{2}{*}{$0.000^{* * *}$} \\
\hline - $\quad$ Incorrect & 48 & 60.00 & 27 & 17.6 & & \\
\hline \multicolumn{7}{|l|}{ Prevention } \\
\hline - $\quad$ Correct & 26 & 32.5 & 60 & 75.0 & \multirow[t]{2}{*}{29.06} & \multirow[t]{2}{*}{$0.000^{* *}$} \\
\hline - incorrect & 54 & 67.5 & 20 & 25.0 & & \\
\hline
\end{tabular}

A statistical significance difference $(P \leq 0.05)$

Table 2, reveals percentage distribution of the studied nurses according to their knowledge about Maple Syrup Urine Disease pre and post program implementation. It clarifies that, there was highly statistical significance pre and post program implementation ( $\mathrm{p}$ value was $0.00^{* * *}$ ).

Table (3): Percentage distribution of the studied nurses according to their practice regarding general observations for children with Maple Syrup Urine Disease pre and post program implementation $(\mathbf{n}=80)$

\begin{tabular}{|c|c|c|c|c|c|c|}
\hline \multirow[t]{2}{*}{ Items } & \multicolumn{2}{|c|}{$\begin{array}{c}\text { Pre program } \\
\text { implementation } \\
(80)\end{array}$} & \multicolumn{2}{|c|}{$\begin{array}{c}\text { Post program } \\
\text { implementation } \\
(80)\end{array}$} & \multirow[t]{2}{*}{$\mathbf{X}^{2}$} & \multirow[t]{2}{*}{ P value } \\
\hline & No & $\%$ & No & $\%$ & & \\
\hline \multicolumn{5}{|c|}{$\begin{array}{l}\text { General observations } \\
\text { A- Assess Skin color and peripheral perfusion }\end{array}$} & \multirow{3}{*}{79.25} & \multirow{3}{*}{$0.00^{* *}$} \\
\hline - Done & 0 & 0.00 & 54 & 67.50 & & \\
\hline - $\quad$ Not done & 80 & 100 & 26 & 32.50 & & \\
\hline \multicolumn{6}{|c|}{ B- Assess if intact / dry / broken (especially skinfolds) } & \multirow{3}{*}{$0.00^{*}$} \\
\hline - Done & 80 & 100 & 61 & 76.30 & \multirow[t]{2}{*}{81.50} & \\
\hline - $\quad$ Not done & 0 & 0.00 & 19 & 23.80 & & \\
\hline \multicolumn{6}{|c|}{ C- Ensure skin is kept clean and dry and nappy changed frequently. } & \multirow{3}{*}{0.05} \\
\hline - Done & 14 & 17.5 & 73 & 91.30 & \multirow[t]{2}{*}{87.69} & \\
\hline - $\quad$ Not done & 66 & 82.5 & 7 & 8.80 & & \\
\hline \multicolumn{6}{|c|}{ D- Hair condition: Assess if dry / brittle. } & \multirow{3}{*}{$0.00^{*}$} \\
\hline - $\quad$ Done & 0 & 0.00 & 60 & 75.0 & \multirow[t]{2}{*}{96.00} & \\
\hline - $\quad$ Not done & 80 & 10 & 20 & 25.0 & & \\
\hline \multicolumn{6}{|l|}{ E- Height \& Weight } & \\
\hline - $\quad$ Done & 12 & 15.00 & 55 & 68.80 & \multirow[t]{2}{*}{47.47} & \multirow[t]{2}{*}{$0.00^{* *}$} \\
\hline - Not done & 68 & 85.00 & 25 & 31.30 & & \\
\hline
\end{tabular}

A statistical significance difference $(\mathbf{P} \leq \mathbf{0 . 0 5})$

Table 3, presents percentage distribution of the studied nurses' according to their practice regarding general observations for children with Maple Syrup Urine Disease pre and post-test, clarifies that, there were highly statistically significant pre and post program implementation ( $\mathrm{p}$ value was $0.00^{* *}$ ), while statistically significant regarding ensuring that, skin was kept clean and dry and nappy changed frequently ( $p$ value was $0.05)$. 
Table (4): Percentage distribution of the studied nurses according to their practice regarding neurological status and Physiological Parameters for children with Maple Syrup Urine Disease pre and post program implementation $(\mathbf{n}=\mathbf{8 0})$

\begin{tabular}{|c|c|c|c|c|c|c|}
\hline \multirow[t]{2}{*}{ Items } & \multicolumn{2}{|c|}{$\begin{array}{c}\text { Pre program } \\
\text { implementation } \\
(80)\end{array}$} & \multicolumn{2}{|c|}{$\begin{array}{c}\text { Post program } \\
\text { implementation } \\
(80)\end{array}$} & \multirow[t]{2}{*}{$\mathbf{X}^{2}$} & \multirow[t]{2}{*}{$\begin{array}{c}\mathbf{P} \\
\text { value }\end{array}$} \\
\hline & No & $\%$ & No & $\%$ & & \\
\hline \multicolumn{5}{|c|}{$\begin{array}{l}\text { Neurological Status and Physiological Parameters } \\
\text { A- Assess neurological status using Glasgow Coma Scale }\end{array}$} & \multirow[t]{3}{*}{109.47} & \multirow{3}{*}{$0.00^{*}$} \\
\hline - Done & 0 & 0.00 & 65 & 81.30 & & \\
\hline - $\quad$ Not done & 80 & 100 & 15 & 18.80 & & \\
\hline \multicolumn{7}{|c|}{ B- Report ataxia, slurred speech, visual disturbances and general disorientation. } \\
\hline - Done & 24 & 30.00 & 60 & 75.00 & \multirow[t]{2}{*}{32.43} & \multirow[t]{2}{*}{$0.00^{*}$} \\
\hline - $\quad$ Not done & 56 & 70.00 & 20 & 25.00 & & \\
\hline \multicolumn{7}{|c|}{$\begin{array}{l}\text { Physiological parameters: } \\
\text { Vital signs: }\end{array}$} \\
\hline - Done & 15 & 18.8 & 58 & 72.50 & \multirow[t]{2}{*}{46.58} & \multirow[t]{2}{*}{$0.00^{*}$} \\
\hline - $\quad$ Not done & 65 & 81.30 & 22 & 27.50 & & \\
\hline \multicolumn{7}{|l|}{ Oxygen saturation } \\
\hline - $\quad$ Done & 25 & 31.3 & 64 & 80.00 & \multirow[t]{2}{*}{38.51} & \multirow[t]{2}{*}{0.05} \\
\hline - $\quad$ Not done & 55 & 68.8 & 16 & 20.00 & & \\
\hline \multicolumn{6}{|c|}{ Check branched chain amino acids in blood } & $0.00^{*}$ \\
\hline - Done & & 56.30 & 67 & 83.80 & \multirow[t]{2}{*}{14.40} & \\
\hline - $\quad$ Not done & & 43.80 & 13 & 16.30 & & \\
\hline \multicolumn{6}{|c|}{$\begin{array}{l}\text { Monitor blood glucose if glycosuria is present and at } 4-6 \text { hourly intervals if } \\
\text { on multiple infusions / high concentration dextrose }\end{array}$} & $0.00^{*}$ \\
\hline - Done & & 15.0 & 75 & 93.80 & \multirow[t]{2}{*}{49.29} & \multirow{2}{*}{0.001} \\
\hline - $\quad$ Not done & 68 & 85.00 & 5 & 6.30 & & \\
\hline
\end{tabular}

A statistical significance difference $(\mathrm{P} \leq \mathbf{0 . 0 5})$

Table 4, percentage distribution of the studied nurses' according to their practice regarding neurological status and physiological parameters for children with Maple Syrup Urine Disease pre and post-test, shows that, there were highly statistically significant pre and post program implementation, while statistically significant regarding Oxygen saturation ( $\mathrm{p}$ value was 0.05 ).

Table (5): Percentage distribution of the studied nurses according to their practice regarding nutrition and medication for children with Maple Syrup Urine Disease pre and post program implementation $(\mathbf{n}=\mathbf{8 0})$

\begin{tabular}{|c|c|c|c|c|c|c|}
\hline \multirow[t]{2}{*}{ Items } & \multicolumn{2}{|c|}{$\begin{array}{c}\text { Pre program } \\
\text { implementation } \\
(80)\end{array}$} & \multicolumn{2}{|c|}{$\begin{array}{l}\text { Post program } \\
\text { implementation } \\
(80)\end{array}$} & \multirow[t]{2}{*}{$\mathbf{X}^{2}$} & \multirow[t]{2}{*}{ P value } \\
\hline & No & $\%$ & No & $\%$ & & \\
\hline \multicolumn{5}{|c|}{$\begin{array}{l}\text { Nutrition and medication } \\
\text { A- Determine child's immediate needs and ongoing management. }\end{array}$} & \multirow[b]{3}{*}{60.67} & \multirow[b]{3}{*}{$0.00^{* *}$} \\
\hline - Done & 2 & 31.30 & 66 & 82.5 & & \\
\hline - $\quad$ Not done & 55 & 68.80 & 14 & 17.5 & & \\
\hline \multicolumn{7}{|c|}{ B- Give Carbohydrate and fat Solution (CHO \& Fat) } \\
\hline - Done & 29 & 36.30 & 61 & 76.30 & \multirow[t]{2}{*}{35.47} & \multirow[t]{2}{*}{0.05} \\
\hline - $\quad$ Not done & 51 & 63.80 & 19 & 23.80 & & \\
\hline \multicolumn{7}{|c|}{ C- Continue usual method of feeding - oral and / or nasogastric feeding } \\
\hline - Done & 26 & 32.5 & 75 & 93.80 & \multirow[t]{2}{*}{30.86} & \multirow[t]{2}{*}{$0.00^{* *}$} \\
\hline - $\quad$ Not done & 57 & 67.50 & 5 & 6.30 & & \\
\hline
\end{tabular}




\begin{tabular}{|c|c|c|c|c|c|c|}
\hline \multicolumn{7}{|c|}{ D- Enteral feeding (nasogastric tubes etc. if required). } \\
\hline - $\quad$ Done & 20 & 25 & 74 & 92.5 & \multirow[t]{2}{*}{42.03} & \multirow[t]{2}{*}{$0.00^{* * *}$} \\
\hline Not done & 60 & 75 & 6 & 7.50 & & \\
\hline \multicolumn{7}{|c|}{ E- Check relevant diet sheets for instructions: } \\
\hline - $\quad$ Done & 17 & 21.30 & 63 & 78.8 & \multirow[t]{2}{*}{86.03} & \multirow[t]{2}{*}{0.05} \\
\hline - $\quad$ Not done & 63 & 78.8 & 17 & 21.30 & & \\
\hline \multicolumn{7}{|l|}{ Medications: } \\
\hline - $\quad$ Done & 41 & 51.30 & 57 & 71.30 & \multirow[t]{2}{*}{13.29} & \multirow[t]{2}{*}{$0.00^{* * *}$} \\
\hline - $\quad$ Not done & 39 & 48.80 & 23 & 28.80 & & \\
\hline
\end{tabular}

A statistical significance difference $(\mathrm{P} \leq \mathbf{0 . 0 5})$

Table 5, Percentage distribution of the studied nurses' according to their practice regarding feeding and medication for children with Maple Syrup Urine Disease pre and post program implementation, shows that, there were highly statistically significant pre and post program implementation, while statistically significant regarding giving carbohydrate and fat solution and checking relevant diet sheets for instructions ( $p$ value was $0.05)$.

Table (6): Percentage distribution of the studied nurses according to their practice regarding blood, urine sampling, and intake and output for children with Maple Syrup Urine Disease pre and post program implementation $(n=80)$

\begin{tabular}{|c|c|c|c|c|c|c|}
\hline \multirow[t]{2}{*}{ Items } & \multicolumn{2}{|c|}{$\begin{array}{c}\text { Pre program } \\
\text { implementation } \\
(80)\end{array}$} & \multicolumn{2}{|c|}{$\begin{array}{c}\text { Post program } \\
\text { implementation } \\
(80)\end{array}$} & \multirow[t]{2}{*}{$\mathbf{X}^{2}$} & \multirow[t]{2}{*}{ P value } \\
\hline & No & $\%$ & No & $\%$ & & \\
\hline \multicolumn{5}{|c|}{$\begin{array}{l}\text { Blood tests: } \\
\text { Analysis of urea and electrolytes and plasma osmolality. }\end{array}$} & \multirow{3}{*}{56.11} & \multirow{3}{*}{$0.00^{* *}$} \\
\hline - Done & 30 & 37.5 & 54 & 67.5 & & \\
\hline - $\quad$ Not done & 50 & 62.50 & 26 & 32.50 & & \\
\hline \multicolumn{7}{|l|}{ Urine samples } \\
\hline - $\quad$ Done & 19 & 23.80 & 70 & 87.50 & \multirow[t]{2}{*}{30.86} & \multirow[t]{2}{*}{$0.00^{* * *}$} \\
\hline - $\quad$ Not done & 61 & 76.30 & 10 & 12.50 & & \\
\hline \multicolumn{7}{|c|}{$\begin{array}{l}\text { Intake and Output: } \\
\text { 1- Calculate mls / kg / 24hrs. }\end{array}$} \\
\hline - Done & 25 & 31.3 & 71 & 88.80 & \multirow[t]{2}{*}{52.47} & \multirow[t]{2}{*}{$0.00^{* *}$} \\
\hline - $\quad$ Not done & 55 & 68.8 & 9 & 11.30 & & \\
\hline \multicolumn{7}{|c|}{ 2- Record losses ( vomit, urine and stool) } \\
\hline - Done & 2 & 2.5 & 60 & 75.00 & \multirow[t]{2}{*}{119.9} & \multirow[t]{2}{*}{$0.00^{\text {*** }}$} \\
\hline - $\quad$ Not done & 78 & 97.50 & 20 & 25.00 & & \\
\hline \multicolumn{7}{|c|}{ 3- Observe closely for signs of fluid overload } \\
\hline - Done & 23 & 28.80 & 73 & 91.30 & \multirow[t]{2}{*}{34.27} & \multirow[t]{2}{*}{$0.00^{* *}$} \\
\hline - $\quad$ Not done & 57 & 71.30 & 7 & 8.80 & & \\
\hline
\end{tabular}

\section{A statistical significance difference $(\mathbf{P} \leq \mathbf{0 . 0 5})$}

Table 6, Percentage distribution of the studied nurses' according to their practice regarding blood and urine sampling and intake and output for children with Maple Syrup Urine Disease pre and post program implementation, illustrates that, there were highly statistically significant pre and post program implementation (p value was $0.00^{* *}$ ). 
Table (7): Percentage distribution of the studied nurses according to their practice regarding ongoing education and genetic implications for parents and their children with Maple Syrup Urine Disease pre and post-program implementation $(n=80)$

\begin{tabular}{|c|c|c|c|c|c|c|}
\hline \multirow[t]{2}{*}{ Items } & \multicolumn{2}{|c|}{$\begin{array}{c}\text { Pre program } \\
\text { implementation } \\
(80)\end{array}$} & \multicolumn{2}{|c|}{$\begin{array}{c}\text { Post program } \\
\text { implementation } \\
(80)\end{array}$} & \multirow[t]{2}{*}{$\mathbf{X}^{2}$} & \multirow[t]{2}{*}{$\begin{array}{c}P \\
\text { value }\end{array}$} \\
\hline & No & $\%$ & No & $\%$ & & \\
\hline \multicolumn{5}{|c|}{ Ongoing education and genetic implications } & \multirow{3}{*}{24.21} & \multirow{3}{*}{$<0.05$} \\
\hline - $\quad$ Done & 28 & 35.00 & 71 & 88.70 & & \\
\hline - $\quad$ Not done & 52 & 65.00 & 9 & 11.30 & & \\
\hline \multicolumn{6}{|c|}{ Well and Unwell Regimens } & \multirow{3}{*}{0.05} \\
\hline - $\quad$ Done & 18 & 22.50 & 61 & 76.30 & \multirow[t]{2}{*}{71.12} & \\
\hline - $\quad$ Not done & 62 & 77.50 & 19 & 23.80 & & \\
\hline \multicolumn{6}{|l|}{ Discharge care } & \multirow{3}{*}{0.05} \\
\hline - $\quad$ Done & 26 & 32.5 & 75 & 93.80 & \multirow[t]{2}{*}{30.86} & \\
\hline - $\quad$ Not done & 57 & 67.50 & 5 & 6.30 & & \\
\hline \multicolumn{6}{|l|}{ Follow up care: } & \\
\hline - $\quad$ Done & 17 & 21.30 & 63 & 78.8 & \multirow[t]{2}{*}{86.03} & \multirow[t]{2}{*}{0.05} \\
\hline - $\quad$ Not done & 63 & 78.8 & 17 & 21.30 & & \\
\hline
\end{tabular}

A statistical significance difference $(\mathrm{P} \leq \mathbf{0 . 0 5})$

Table 7, Percentage distribution of the studied nurses' according to their practice regarding ongoing education for parents and their children with Maple Syrup Urine Disease pre and post-test, clarifies that, there were statistically significant regarding well and unwell regimes, discharge care, and follow up care ( $p$ value was 0.05), while a statistical significance difference pre and post program implementation regarding genetic implications $(\mathrm{P}<0.05)$.

Table (8): Percentage distribution of the studied nurses' total knowledge and total practice regarding Maple Syrup Urine Disease $(\mathbf{n}=\mathbf{8 0})$

\begin{tabular}{|c|c|c|c|c|c|c|}
\hline \multirow[t]{2}{*}{ Items } & \multicolumn{2}{|c|}{$\begin{array}{c}\text { Pre program } \\
\text { implementation } \\
(80)\end{array}$} & \multicolumn{2}{|c|}{$\begin{array}{c}\text { Post program } \\
\text { implementation } \\
(80)\end{array}$} & \multirow[t]{2}{*}{$\mathbf{X}^{2}$} & \multirow[t]{2}{*}{$P$ value } \\
\hline & No & $\%$ & No & $\%$ & & \\
\hline \multicolumn{5}{|l|}{ Total knowledge } & \multirow{3}{*}{$\begin{array}{c}120.0 \\
4\end{array}$} & \multirow{3}{*}{$0.00^{* *}$} \\
\hline - $\quad$ Satisfactory & 9 & 11.20 & 77 & 96.25 & & \\
\hline - Unsatisfactory & 71 & 88.80 & 3 & 3.75 & & \\
\hline \multicolumn{7}{|l|}{ Total practice } \\
\hline - Competent & 10 & 12.5 & 71 & 88.80 & \multirow[b]{2}{*}{55.12} & \multirow[t]{2}{*}{$0.00^{* *}$} \\
\hline - incompetent & 70 & 87.5 & 9 & 11.30 & & \\
\hline
\end{tabular}

A statistical significance difference $(\mathrm{P} \leq \mathbf{0 . 0 5})$

Table 8, percentage distribution of the studied nurses' total knowledge and total practice regarding Maple Syrup Urine Disease shows that, before implementation of the program, the majority of nurses (88.8 \& 87.5) have unsatisfactory knowledge and incompetent practice regarding management of children with MSUD respectively. In contrast, after implementation of the program, the highest percentage of nurses $(96.25 \% \&$ $88.8 \%$ ) have satisfactory knowledge and competent practice respectively. 
Table (9): Correlation between total nurses' knowledge, total practice and their personal characteristics regarding Maple Syrup Urine Disease (n=80)

\begin{tabular}{|l|c|c|}
\hline \multirow{2}{*}{ Items } & \multicolumn{2}{|c|}{ Total knowledge } \\
\cline { 2 - 3 } & $\mathbf{r}$ & P Value \\
\hline - Total practice & 0.481 & $0.00^{*}$ \\
\hline - Age of the nurses & 0.004 & 0.959 \\
\hline - Qualifications & 0.039 & 0.629 \\
\hline - Gender & 0.017 & 0.834 \\
\hline
\end{tabular}

Table 9, Shows correlation between nurses' knowledge and practice and their personal characteristics after implementation of the program. This table illustrates positive statistically significance correlation between total nurses' knowledge and practice score $(0.481, \mathrm{p} 0.00)$.

\section{Discussion}

Maple Syrup Urine Disease (MSUD) is a recessively inherited inborn error of metabolism characterized by the inability to metabolize the branched chain amino acids leucine, isoleucine, and valine, hence, resulting in their accumulation in the blood. The name of the disease derives from the characteristic sweet maple syrupy smell of urine in affected children. The condition appears in early infancy, where it is characterized by feeding difficulties and refusal of food, vomiting, seizures, lack of energy, and even coma. So, if those children left untreated, the accumulation of the amino acids and their keto acids leads to serious complications, including encephalopathy and progressive neuro-degeneration (Centre for Arab Genomic Studies, 2016).

As regards to the studied nurses' personal characteristics, the total number of the studied sample was eighty nurses; nearly two thirds of their ages ranging from 20 to less than 30 years, and the majority of them were females that might be due to the greater fraction of the nurses in Egypt was female and may also related to the studying of nursing in the Egyptian Universities was exclusive for females only till ten years ago. More than three quarters of them were having diploma of nursing school. As well, more than three quarters of them are having 1 to 10 years of experiences. This result agreed with the result carried out in Egypt; Shahin, (2012) in a study about " Nurses' Knowledge and Practices regarding Enteral Nutrition at the Critical Care Department of Al-Manial University Hospital in Egypt: Impact of a Designed Instructional Program" who found in his study on eighty five nurses carried out in Al-Manial university Hospital that about three quarters of the studied nurses were females, more than one third of them their age was ranged between 25 to less than 34 years and one quarter between 35 and less than 45 years. More than half of them were diploma nurses with more than ten years of experience.

Concerning the age and gender distribution of the studied children fulfilling the inclusion criteria; their ages ranged from less than one year to less than 10 years with a mean of $(6.98+2.28$ year). These results in agreement with Kong \& Rajikan, (2015) in a study carried out in Kuala Lumpur about "Growth and nutritional status of children with maple syrup urine disease (MSUD): A 6-months follow up study in Institute of Pediatric, Hospital Kuala Lumpur (HKL)" who summarizes the results with regard to characteristic of all MSUD children aged between 1 and 12 years, and the mean age was $6.54 \pm 3.27$ years. There were $67.3 \%$ males with MSUD, these results in accordance with Yunus et al., 2011 in a study carried out in Malaysia about "Clinical and biochemical profiles of maple syrup urine disease in Malaysian children" who found that the majority (52 per cent) of the cases were found to occur in males. Additionally these results disagree with Kong \& Rajikan, (2015) who found that (36.4 per cent) male and (63.6 per cent) female children. Indeed, MSUD is inherited in an autosomal recessive manner; thus, it affects both males and females equally (Frazier et al., 2014).

Regarding nurses' knowledge about MSUD, the findings of the current study reflected that, the total scores of nurses' knowledge before program implementation was unsatisfactory. This may be due to lack of training programs in this field, unavailability of guidelines for management of children with MSUD, lack of multidisciplinary team cooperation, lack of nurses' motivations and lack desires to improve their knowledge. These findings go in line with Sabaq \& Said (2015) in a study in Egypt about "Effect of educational program on nurses' performance regarding safe medications administration through nasogastric tube among critically ill children" and found that all nurses had unsatisfactory level of knowledge.

However, after implementation of the program, there was a significant improvement in the total knowledge scores of nurses who achieve satisfactory level of knowledge. These findings are agreed with the hypothesis number one in the current study. The improvement scores indicated that, the program 
implementation was a successful method for increasing nurses' knowledge regarding MSUD in children. These findings are consistent with findings of $\mathbf{L e e} \boldsymbol{\&} \mathbf{L i n , ( 2 0 1 3 )}$ in a study about " The effectiveness of an e-learning program on pediatric medication safety for undergraduate students: A pretest-post-test intervention study " they found that there was a significant gain of nurses' knowledge after program implementation.

One important aspect to consider is that, most nurses after program implementation gave correct knowledge regarding MSUD. This may be due to the educational program was effective and successful method for increasing their knowledge which in turn contribute in reducing malpractice regarding management of children with MSUD. This is proved with Robinson \& Drumm (2001) in a study about " Maple Syrup Disease: A Standard of Nursing Care" who stated that, The care provider's knowledge of the pathophysiology of MSUD and thoughtful care addressing neurological status, cerebral edema, fluid and electrolyte management, nutrition, education, and psychosocial issues may enable the ill child to make a full recovery without serious sequelae.

Regarding nurses' practices about MSUD, the finding of the present study revealed that, the majority of nurses had incompetent practices before program implementation. As well as these findings are in agreement with a study carried out by Robinson \& Drumm (2001) who assess the nurses' practices regarding management of children with MSUD and they found that nurses had incompetent practices. In the same line, these findings in agreement with Kong \& Rajikan, (2015) in a study carried out in Kuala Lumpur about "Growth and nutritional status of children with maple syrup urine disease (MSUD): A 6-months follow up study in Institute of Pediatric, Hospital Kuala Lumpur (HKL)", who found that, nurses had incompetent practices regarding MSUD.

Nevertheless, after program implementation there was a highly statistical significant improvement for nurses who achieve competent scores regarding MSUD. These findings match with the hypothesis number two. This may be due to the program makes refreshment in nurses' knowledge, which in turn led to improvement in their practice. These results in accordance with Batrof \& Mansour, (2012) mentioned that continues educational training programs for nurses are required to maintain competent level in practice.

Apparently, the present study findings proved that there was positive correlation between nurses' knowledge and practices scores after program implementation. This explains those nurses' practices directly influenced by their knowledge and knowledge is essential to achieve best practices. Additionally, there is a strong positive correlation between nurses' knowledge and practices scores and knowledge is important for competent nursing practices.

The results of the current study revealed that, there was highly statistically significant relation between nurses' knowledge with age, and practices scores after program implementation. This relation may be due to the fact that the youngest nurses are new graduated, cooperative, and more receptive with higher education and memory abilities than those with oldest nurses. These results are inconstant with Abdullah et al., (2014) in a study carried out in Egypt about "Nurses' Knowledge and Practices about Administration of Medications via Nasogastric Tube among Critically Ill Patients" who found that there were no significant correlation between the age of participants and their knowledge and practices scores.

Regarding relation between knowledge, practices scores and nurses' level of qualification, the present study findings revealed that there were a highly statistically significant relation between nurses' level of education with knowledge, and practice scores after program implementation. These findings are in agreement with Hamed, (2009) in a study carried out in Egypt about "Nurses performance during cardio-pulmonary resuscitation in Intensive Care Unit and Cardiac Care Unit at Benha University hospital" who reported that Bachelor degree nurses knowledge and practices scores were significantly better than diploma nurses because of their basic knowledge and practice received during academic years, which is different than that received by diploma nurses.

Regarding gender of the studied nurses, the present study revealed that there was no statistically significant relation between gender of nurses with knowledge and practices scores after program implementation. This may be due to that there are many others factors affect knowledge and practice of nurses such as receiving training program, availability of written guidelines and resources. These results were exactly with Sabaq \& Said (2015) in a study carried out on Egypt about "Effect of educational program on nurses' performance regarding safe medications administration through nasogastric tube among critically ill children" and found that there was no significant correlation between male and female nurses with their knowledge and practices scores regarding safe drugs administration via nasogastric tube.

\section{Conclusion:}

Based on the results of the current study, it can be concluded that, the educational program is highly effective and successful method to upgrade nurses' knowledge, and enhancing their practice regarding MSUD. However, there was statistically significant positive correlation between nurses' knowledge, and practices scores 
after program implementation. As well as, there were highly statistically significant relation between nurses' knowledge and practices scores with their age and qualifications post program implementation.

\section{Recommendations}

In the light of the findings of the current study, the following recommendations are suggested:

1. Continuous education and training sessions should be provided for nurses regarding MSUD to ensure satisfactory knowledge and competent practices.

2. Printed universal guidelines and simple handouts regarding MSUD should be available for guiding nurses' practice.

3. Collaborative interaction with nurses and health care team will assure safe practice regarding MSUD.

4. Further study can be replicated on other Hospitals using a large sample size to generalize the findings.

\section{Acknowledgements:}

Deepest thanks to hospital administration for their permission, cooperation, and kindly help during the practical part of the work. We express our gratitude and thanks towards all the participated nurses who accepted to participate in this study.

\section{Limitations of the study:}

Limited nurses cooperation during implementation of the program.

[1]. Abdullah, M., Mohammed, W., and Ismail, M. (2014): Nurses' Knowledge and Practices about Administration of Medications via Nasogastric Tube among Critically Ill Patients, Journal of Education and Practice, 5(1): PP: 147-159.

[2]. Batrof, M., and Mansour, K. (2012): Management principles for health professionals, (5th ed). Lippincott Company: Philadelphia, p.141.

[3]. Centre for Arab Genomic Studies, (2016): A Division of Sheikh Hamdan Award for Medical Sciences, the Catalogue for Transmission Genetics in Arabs CTGA Database. Available at: http://www.cags.org.ae/ctga/details.aspx?id=199

[4]. Frazier, D.M., Allgeier, C. and Homer, C. (2014): Nutrition management guideline for maple syrup urine disease: an evidence- and consensus-based approach, Molecular Genetic Metabolism, Vol. 112 No. 3, pp: 210-217.

[5]. Hamed, M. (2009): Nurses performance during cardio-pulmonary resuscitation in Intensive Care Unit and Cardiac Care Unit at benha University hospital, Master thesis, Faculty of Nursing, Benha University, PP: 101-106.

[6]. Hockenberry, M. \& Wilson, D. (2011). Wong's Clinical Manual of Pediatric Nursing. $8^{\text {th }}$ ed., London: Mosby, pp: 652-658

[7]. Hoffmann B, Helbling C, Schadewaldt P, Wendel U. (2006): Impact of longitudinal plasma leucine levels on the intellectual outcome in patients with classic MSUD. Pediatr Res. Jan. 59 (1), PP:17-20.

[8]. Joshi SN, Venugopalan P., (2007): Clinical characteristics of neonates with inborn errors of metabolism detected by Tandem MS analysis in Oman. Brain Dev PMID, 1731402

[9]. Kong $\boldsymbol{J P} \quad \&$ Rajikan $\boldsymbol{R} \boldsymbol{B}$, (2015): Growth and nutritional status of children with maple syrup urine disease (MSUD): A 6-months follow up study in Institute of Pediatric, Hospital Kuala Lumpur (HKL) Nutrition \& Food Science, Vol. 45 Iss: 2, pp.286 - 301. DOI http://dx.doi.org/10.1108/NFS-08-20140077

[10]. Lee, T., \& Lin, F. (2013): The effectiveness of an e-learning program on pediatric medication safety for undergraduate students: A pretest-post-test intervention study. Nurse Education Today, P, 33, 378383.

[11]. Mazariegos GV, Morton DH, Sindhi R, Soltys K, Nayyar N, Bond G, et al.(2012): Liver Transplantation for Classical Maple Syrup Urine Disease: Long-Term Follow-Up in 37 Patients and Comparative United Network for Organ Sharing Experience. J Pediatric, 160, PP:116-121

[12]. National Centre for Inherited Metabolic Disorders,( 2014): Long-term follow-up and outcome of maple syrup urine disease. Advisory Group for National Specialised Services. http://www.metabolic.ie

[13]. Park HD, Lee DH, Hong YH, Kang DH, Lee YK, Song J, et al. (2011): Three Korean patients with maple syrup urine disease: four novel mutations in the BCKDHA gene. Ann Clin Lab Sci. Spring. 41(2), PP:167-73. 
[14]. Quental S, Macedo-Ribeiro S, Matos R, Vilarinho L, Martins E, Teles EL, et al. (2008): Molecular and structural analyses of maple syrup urine disease and identification of a founder mutation in a Portuguese Gypsy community. Mol Genet Metab. 2008 Jun. 94(2), PP: 148-56.

[15]. Right Diagnosis, (2012): Inherited metabolic disorders statistics by country. Available at: www.right diagnosis.com

[16]. Robinson, D., \& Drumm, L. A. (2001). Maple syrup disease: a standard of nursing care. Pediatric nursing, 27(3), PP: 255-255.

[17]. Sabaq A. G., \& Said K. M., (2015): Effect of educational program on nurses' performance regarding safe medications administration through nasogastric tube among critically ill children, Egyptian Journal of Health Care / Ain Shams - Volume 6 (4), pp: 111-132

[18]. Shahin, M., Mohammed, W., \& Sayed, M. (2012). Nurses' Knowledge and Practices regarding Enteral Nutrition at the Critical Care Department of Al-Manial University Hospital in Egypt: Impact of a Designed Instructional Program. Journal of American Science, 8 (11), PP: 397-405.

[19]. Singh, R.H., Rohr, F., and Splett, P.L. (2013): Bridging evidence and consensus methodology for inherited metabolic disorders: creating nutrition guidelines J. Eval. Clin. Pract. ; 19, PP: 584-590

[20]. Wilcken, B. (2012): Clinical practice and the development of evidence, Journal of Inherited Metabolic Disorders. 35: 3-4

[21]. Yunus, Z.M., Kamaludin, D.A. and Mamat, M. (2011): Clinical and biochemical profiles of maple syrup urine disease in Malaysian children, Journal Inherited Metabolic Disease Reports, Vol. 5, pp: 99107.

[22]. Yamaguchi K., Wakimizu R., Kubota M., (2016): Difficulties in Daily Life and Associated Factors, and QoL of Children with Inherited Metabolic Disease and Their Parents in Japan: A Literature Review, SSIEM and Springer-Verlag Berlin Heidelberg, JIMD Reports, DOI 10.1007/8904_2016_573 Available at: https://www.researchgate.net/publication/304456542_ 